\title{
Ferrous Mordanting of Camel Hair with Thiourea Dioxide
}

\author{
Ariyajavin Khishigsuren, NAKAJIMA Masaru and TAKAHASHI Masaoki \\ Faculty of Textile Science, Kyoto Institute of Technology, Sakyo-ku, Kyoto 606-8585 Japan
}

Received 16 October 2000; accepted for publication 14 December 2000

\begin{abstract}
The method of mordanting has been found, which gives rise to the solution of the serious problems - discoloring and excessive damaging of bleached fiber $\rightarrow$ associated with the mordant bleaching. Under the appropriate conditions, a mixture of thiourea and hydrogen peroxide in the molar ratio of $1: 2$ in an aqueous solution forms thiourea dioxide, which could be decomposed to produce a reductive substance. This formed reductive substance is found to be an effective reducing agent, when applied during the mordanting. Under the conventional conditions of mordanting, thiourea dioxide provides a better whiteness with less damage than citric acid, which is the most effective reducing agent among the auxiliaries applicable during mordanting. Moreover, the conditions of mordanting are established under which thiourea dioxide provides its maximum whiteness with reduced damage.
\end{abstract}

Key Words: Camel hair, mordant bleaching, thiourea dioxide, mordanting conditions, bleaching effect. 